07

\title{
Гибридные солнечные элементы с системой концентрации оптического излучения
}

\author{
(C) В.С. Калиновский ${ }^{1}$, Е.В. Контрош ${ }^{1, \uparrow, ~ А . В . ~ А н д р е е в а ~}{ }^{1}$, В.М. Андреев ${ }^{1}$, В.В. Малютина-Бронская ${ }^{2}$, \\ В.Б. Залесский ${ }^{2}$, А.М. Лемешевская ${ }^{3}$, В.И. Кузоро ${ }^{4}$, В.И. Халиманович ${ }^{4}$, М.К. Зайцева \\ ${ }^{1}$ Физико-технический институт им. А.Ф. Иофрфе РАН, Санкт-Петербург, Россия \\ ${ }^{2}$ ГНПО „Оптика, оптоэлектроника и лазерная техника“, Минск, Беларусь \\ ${ }^{3}$ Филиал НТЦ „Белмикросистемы“ ОАО „Интеграл“ - управляющая компания холдинга „ИНТЕГРАЛ“, Минск, Беларусь \\ ${ }^{4}$ АО „Информационные спутниковые системы“ им. акад. М.Ф. Решетнёва, Красноярск, Россия \\ ${ }^{5}$ Научно-исследовательский институт космических систем им. А.А. Максимова - филиал ФГУП \\ „Государственный космический научно-производственный центр им. М.В. Хруничева, Москва, Россия \\ 『 E-mail: kontrosh@mail.ioffe.ru
}

Поступило в Редакцию 7 мая 2019г.

В окончательной редакции 7 мая 2019 г.

Принято к публикации 13 мая 2019г.

\begin{abstract}
Разработаны и исследованы гибридные солнечные элементы (СЭ) на базе СЭ $\mathrm{InGaP} / \mathrm{Ga}(\mathrm{In}) \mathrm{As} / \mathrm{Ge}$ и $\mathrm{Si}$, интегрированных в кристаллическое кремниевое теплоотводящее основание, с системой концентрирования оптического излучения на основе линейных линз Френеля и углепластиковой несущей конструкции. Данные гибридные элементы с линейными концентраторами солнечного излучения в фотоэлектрическом модуле обеспечивают удельную электрическую мощность $390 \mathrm{~W} / \mathrm{m}^{2}\left(\mathrm{AM} 0,1367 \mathrm{~W} / \mathrm{m}^{2}\right.$ ) и снижение удельного веса фотогенерирующей части до $1.0 \mathrm{~kg} / \mathrm{m}^{2}$. Улучшенные фотоэлектрические характеристики и радиационная стойкость позволяют использовать созданные гибридные элементы с концентраторами излучения в космических солнечных батареях и автономных энергетических установках с концентрированием солнечного излучения.
\end{abstract}

Ключевые слова: многопереходный солнечный элемент, гибридный солнечный элемент, линейная линза Френеля, концентраторный фотоэлектрический модуль, солнечная батарея.

DOI: 10.21883/PJTF.2019.16.48159.17868

Актуальной задачей космической солнечной энергетики является создание солнечных батарей с высокими энергетическими и эксплуатационными характеристиками. Повышение эффективности многопереходных солнечных элементов на основе соединений А3В5 может быть достигнуто при использовании систем концентрирования солнечного излучения с обеспечением эффективных условий отвода тепла в окружающую среду, например в составе концентраторного фотоэлектрического модуля (КФЭМ).

Многопереходные солнечные элементы достигают максимального КПД при преобразовании концентрированного солнечного излучения в широком температурном диапазоне и обеспечивают хорошую радиационную стойкость [1-4]. При создании элементарного КФЭМ требуется обеспечить высокую эффективность как линейных линзовых концентраторов оптического излучения в требуемом спектральном диапазоне, так и солнечных элементов (СЭ) при эффективном рассеивании в пространство остаточного тепла [5-7]. Исходя из этих требований был разработан и изготовлен гибридный солнечный элемент (ГСЭ) для КФЭМ. ГСЭ включает в себя фотоактивное кристаллическое кремниевое теплоотводящее основание (ТО) и смонтированные на нем электрогенерирующие линейки из СЭ $\mathrm{InGaP} / \mathrm{Ga}(\mathrm{In}) \mathrm{As} / \mathrm{Ge}$ (рис. 1).
Для предотвращения инверсии проводимости под слоем окисла по поверхности интегрированных в ТО кремниевых солнечных элементов (рис. 1) было осуществлено ионное легирование бором с флюенсом $F_{i}=(5.0-20) \cdot 10^{13} \mathrm{ion} / \mathrm{cm}^{2}$. Для предотвращения утечек между кремниевыми $n^{+} / p$-диодами каждый интегрированный кремниевый солнечный элемент окружен сильнолегированными охранными кольцами $p^{+}$-типа $\left(F_{i}=1.9 \cdot 10^{15} \mathrm{ion} / \mathrm{cm}^{2}\right)$. Для повышения величины пробивного напряжения изоляции при $T=1000^{\circ} \mathrm{C}$ был выполнен отжиг с разгонкой областей $n^{+} / p$-диодов и $p^{+}$-охранных колец.

В конструкции кремниевого СЭ заложены два уровня металлизации. Путем напыления $\mathrm{AlSi}$ толщиной $0.45 \mu \mathrm{m}$ формируется первый уровень металлизированной разводки, обеспечивающий низкоомный контакт к $n^{+}$-областям интегрированных в ТО кремниевых СЭ. В качестве межуровневого диэлектрика использован двухслойный материал из плазмохимических (ПХ)

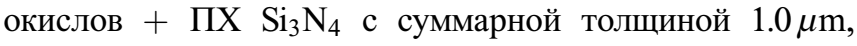
обеспечивающий изоляцию между металлизированными уровнями и СЭ. Второй уровень металлизированной разводки формировался осаждением металлов $\mathrm{Ti}-\mathrm{Ni}$ толщиной $1.2 \mu \mathrm{m} \mathrm{c}$ последующим электрохимическим усилением золотом. Результаты измерений на ГСЭ удельного сопротивления $\left(R_{S}\right)$ между контактными пло- 


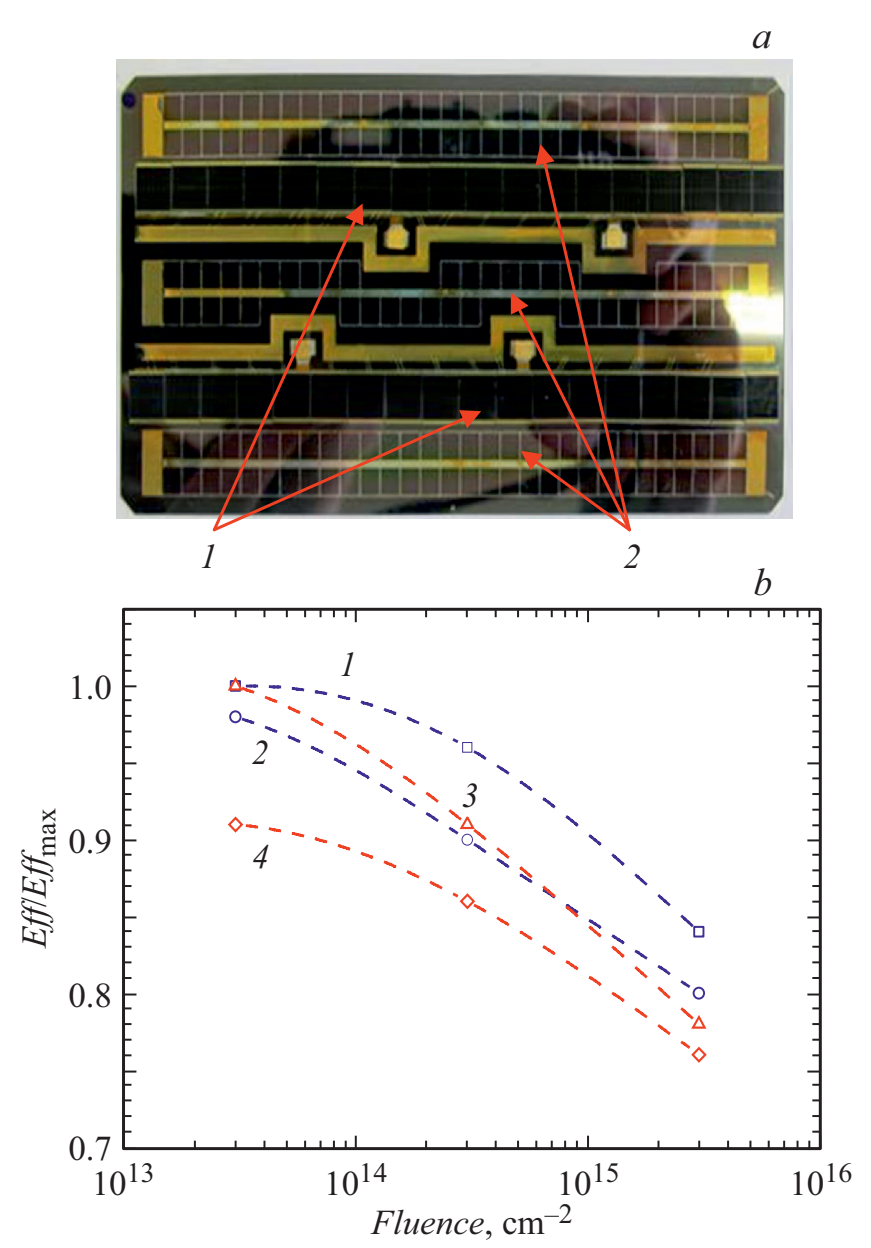

Рис. 1. $a$ - образец гибридного солнечного элемента с габаритным размером кремниевого теплосбрасывающего основания $0.25 \times 54 \times 104 \mathrm{~mm}: 1-$ электрогенерирующие линейки из СЭ $\mathrm{InGaP} / \mathrm{Ga}(\mathrm{In}) \mathrm{As} / \mathrm{Ge}, 2$ - интегрированные в теплосбрасывающее $\mathrm{Si}-о$ снование кремниевые СЭ. $b-$ зависимости КПД гибридного солнечного элемента от флюенса электронов с энергией $1 \mathrm{MeV}: 1,2$ - для электрогенерирующих линеек из CЭ $\mathrm{InGaP} / \mathrm{Ga}(\mathrm{In}) \mathrm{As} / \mathrm{Ge}, 3,4$ - для кремниевых CЭ, 1, 3 - в составе модуля, 2, 4 - вне его.

щадками и кремниевыми солнечными элементами показали, что $R_{S}>10^{10} \Omega$ при приложении напряжения смещения величиной $10 \mathrm{~V}$ и более.

На токоведущие контактные шины $p$-кремниевого ТО вакуумной пайкой монтировались утоненные до $50 \mu \mathrm{m}$ CЭ $\mathrm{InGaP} / \mathrm{Ga}(\mathrm{In}) \mathrm{As} / \mathrm{Ge}$. Трехпереходные CЭ были изготовлены по технологии, изложенной в работах $[3,4]$, позволившей повысить КПД многопереходных СЭ до 35\% при кратности концентрирования солнечного излучения порядка 10 солнц (АМ0, $\left.1367 \mathrm{~W} / \mathrm{m}^{2}\right)$.

В качестве концентратора солнечного излучения в КФЭМ использовалась сдвоенная линейная линза Френеля с фокусом $32 \mathrm{~mm}$ и оптической площадью каждой линзы $5 \times 10 \mathrm{~cm}$ (рис. 2,a). Эффективность разработанных линейных линзовых концентраторов типа линз Френеля составила 90\% при измерениях на импульсном имитаторе солнечного излучения (АМ0, $\left.1367 \mathrm{~W} / \mathrm{m}^{2}\right)$. Несущая углепластиковая конструкция модуля (рис. 2,a) разработана таким образом, чтобы при минимальных весовых характеристиках обеспечить оптимальное плоскопараллельное размещение линейных линзовых концентраторов и гибридных солнечных элементов, ослабив влияние механических воздействий от несущего корпуса к линзовому блоку при термоциклировании и вибрационных нагрузках. Особенность разработанной конструкции заключается в использовании полноразмерного сдвоенного линзового блока и ГСЭ, равных между собой по размерам, и в то же время независимых элементов всей конструкции с передачей им части механических функций [8]. Это обеспечивает хорошую технологичность при изготовлении и сборке с возможностью
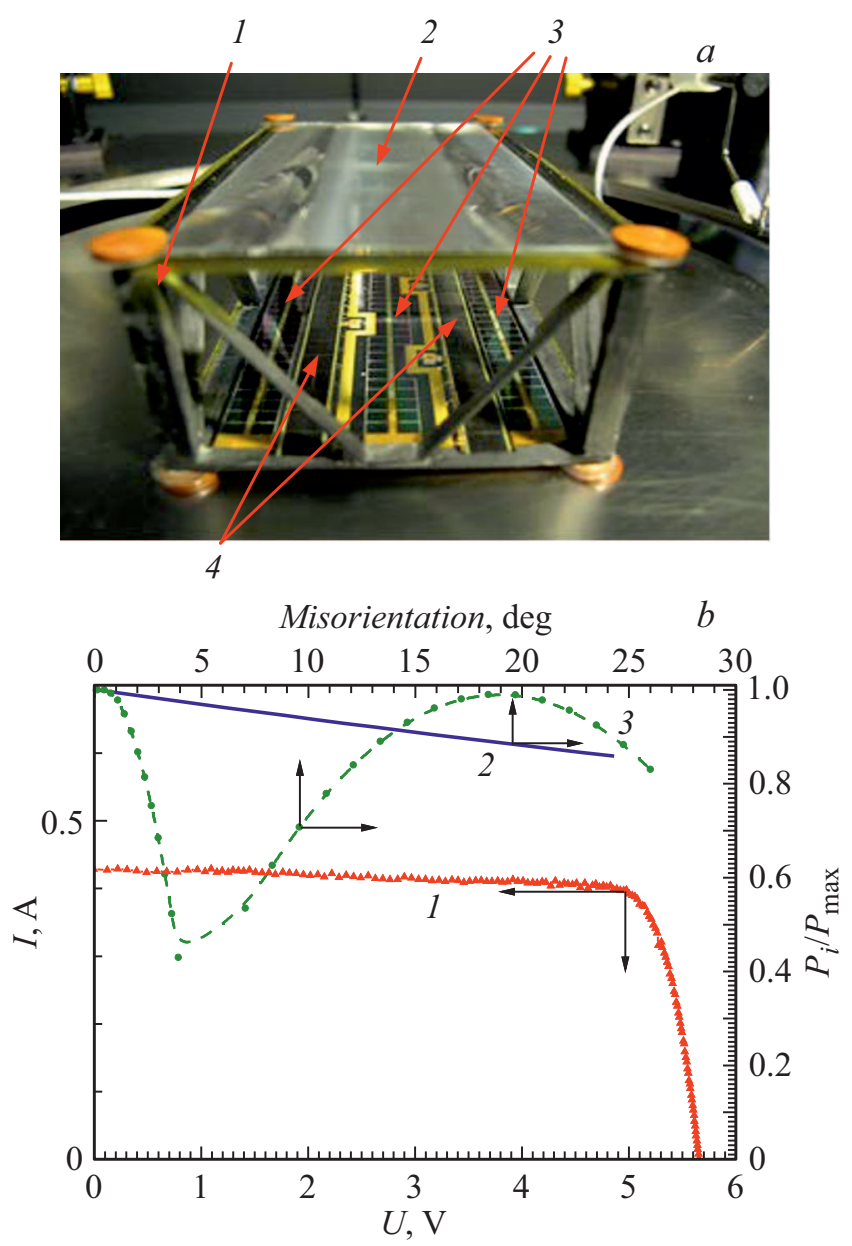

Рис. 2. $a-$ фотография концентраторного фотоэлектрического модуля: несущая углепластиковая рама (1), сдвоенный линейный линзовый концентратор (2), ГСЭ на основе кремниевого ТО с тремя интегрированными кремниевыми СЭ (3) и электрогенерирующих линеек из СЭ $\mathrm{InGaP} / \mathrm{GaAs} / \mathrm{Ge}$ (4). $b$ - световая характеристика модуля для последовательно включенных электрогенерирующих линеек при засветке на импульсном имитаторе коллимированного солнечного излучения (АМ0, $1367 \mathrm{~W} / \mathrm{m}^{2}$ ) (кривая 1) и разориентационные характеристики модуля вдоль линии фокуса (кривая 2) и перпендикулярно линии фокуса (кривая 3). 
последующего мультиплицирования в полномасштабные панели солнечных батарей с концентраторами.

Измерения световых (нагрузочных) вольт-амперных характеристик ГСЭ и КФЭМ выполнены на импульсном имитаторе коллимированного солнечного излучения AM0 $\left(1367 \mathrm{~W} / \mathrm{m}^{2}\right)$. Световая вольт-амперная характеристика КФЭМ для двух последовательно включенных электрогенерирующих линеек из СЭ In GaP/Ga(In)As/Ge гибридного солнечного элемента представлена на рис. $2, b$ (кривая 1 ). Коэффициент полезного действия КФЭМ с ГСЭ составил $28.7 \%$, а выходная удельная электрическая мощность модуля более $390 \mathrm{~W} / \mathrm{m}^{2}$. Теплоотводящее основание на базе кристаллического кремния размером $54 \times 104 \mathrm{~mm}$ и толщиной $0.25 \mathrm{~mm}$ позволяет при средней кратности концентрирования 10 солнц и более $\left(\mathrm{AM} 0,1367 \mathrm{~W} / \mathrm{m}^{2}\right)$ осуществить эффективный отвод остаточного тепла от утоненных многопереходных СЭ и увеличить благодаря интегрированным в них кремниевым СЭ допустимый угол разориентации КФЭМ в направлении, перпендикулярном оси линии фокуса.

Разориентационные характеристики КФЭМ представлены на рис. 2, $b$. Кривые 2 и 3 на этом рисунке показывают изменения мощности вдоль линейного фокуса и перпендикулярно фокусу соответственно. Допустимая разориентация КФЭМ составляет в двух ортогональных направлениях более $\pm 23^{\circ}$.

Образцы ГСЭ были подвергнуты при комнатной температуре облучению электронами с энергией $1 \mathrm{MeV}$ в диапазоне флюенсов $3 \cdot 10^{13}-3 \cdot 10^{15} \mathrm{~cm}^{-2}$ как в составе КФЭМ, так и вне его. На рис. $1, b$ показано изменение КПД электрогенерирующей линейки из СЭ $\mathrm{InGaP} / \mathrm{Ga}(\mathrm{In}) \mathrm{As} / \mathrm{Ge}$ (кривые 1,2 ) и интегрированного в ТО кремниевого СЭ (кривые 3, 4). Видно, что в составе КФЭМ снижение КПД электрогенерирующих линеек и интегрированных кремниевых СЭ при достижении флюенса $1 \cdot 10^{15} \mathrm{~cm}^{-2}$ составило 10 и $15 \%$ соответственно. В то же время при этом же значении флюенса облучения, но вне КФЭМ величина деградации КПД элементов гибридного СЭ примерно в 1.5 раза больше. Удельный вес фотогенерирующей части КФЭМ гибридный солнечный элемент и линейный линзовый концентратор составил $\sim 1.0 \mathrm{~kg} / \mathrm{m}^{2}$.

Исходя из полученных результатов можно полагать, что снижение выходной электрической мощности разработанных ГСЭ в составе КФЭМ при эксплуатации, например, на геостационарной орбите в течение 20 лет составит не более $20 \%$.

Разработаны гибридные солнечные элементы, состоящие из утоненных до $50 \mu \mathrm{m}$ СЭ $\mathrm{InGaP} / \mathrm{Ga}(\mathrm{In}) \mathrm{As} / \mathrm{Ge}$ и фотоактивных теплоотводящих оснований из кристаллического кремния размером $54 \times 104 \mathrm{~mm}$ и толщиной $0.25 \mathrm{~mm}$ с тремя интегрированными кремниевыми солнечными элементами. КФЭМ на основе разработанного гибридного солнечного элемента с линейными линзовыми концентраторами на импульсном имитаторе солнечного излучения (АМ0, $\left.1367 \mathrm{~W} / \mathrm{m}^{2}\right)$ обеспечил
КПД, равный 28.7\%, и удельную выходную электрическую мощность более $390 \mathrm{~W} / \mathrm{m}^{2}$. Использование разработанных гибридных солнечных элементов и линзовых концентраторов позволяет снизить удельную массу фотогенерирующей части до $1.0 \mathrm{~kg} / \mathrm{m}^{2}$ с возможностью мультиплицирования в полномасштабные панели солнечных батарей. Солнечные батареи, созданные на основе разработанных КФЭМ, будут иметь сниженную пропорционально кратности концентрирования солнечного излучения стоимость и при этом обладать радиационной стойкостью со сроком эксплуатации на геостационарных орбитах до 20 лет.

\section{Конфликт интересов}

Авторы заявляют, что у них нет конфликта интересов.

\section{Список литературы}

[1] Alferov Zh.I., Andreev V.M., Rumyantsev V.D. III-V solar cells and concentrator arrays // High-efficient low-cost photovoltaics. Springer Ser. in Optics Sciences. V. 140 / Ed. V. Petrova-Koch, R. Hezel, A. Goetzberg. Springer, 2009. P. 101-141.

[2] Strobl G., LaRoche G., Rash K.D., Hey G. From extraterrestrial to terrestrial applications // High-efficient lowcost photovoltaics. Springer Ser. in Optics Sciences. V. $140 /$ Ed. V. Petrova-Koch, R. Hezel, A. Goetzberg. Springer, 2009. P. 7-27.

[3] Kalinovsky V.S., Grebenshchikova E.A., Dmitriev P.A., Ilinskaya N.D., Kontrosh E.V., Malevskaya A.V., Usikova A.A., Andreev V.M. // AIP Conf. Proc. 2014. V. 1616. P. 326-330.

[4] Kontrosh E.V., Malevskaya A.V., Lebedeva N.M., Kalinovskiy V.S., Andreev V.M. // J. Phys.: Conf. Ser. 2016. V. 690. P. 012036.

[5] O'Neill M., McDanal A.J., Brandhorst H., Spence B., Iqbal S., Sharps P., McPheeters C., Steinfeldt J., Piszczor M., Myers M. Space photovoltaic concentrator using robust fresnel lenses, 4-junction cells, graphene radiators, and articulating receivers // Proc. of IEEE 43th Photovoltaic Specialist Conf. (PVSC). Portland, Oregon, 2016. P. 1337-1342.

[6] Michel C., Loicq J., Languy F., Habraken S. // Solar Energy Mater. Solar Cells. 2014. V. 120. Pt A. P. 183-190.

[7] O'Neill M., McDanal A.J., Piszczor M., Myers M., Sharps P., McPheeters $C$., Steinfeldt $J$. Line-focus and point-focus space photovoltaic concentrators using robust fresnel lenses, 4-junction cells, \& graphene radiators // Proc. of IEEE 44th Photovoltaic Specialist Conf. (PVSC). Washington, DC, 2017. P. 525-530.

[8] Kuzoro V., Khalimanovich V., Kalinovskiy V., Vasileva $T$. Patent RU N 2014127672. Publ. 07.07.2014. 